\title{
FORMULATION AND EVALUATION OF GEL LOADED WITH MICROSPHERES OF APREMILAST FOR TRANSDERMAL DELIVERY SYSTEM
}

\author{
N. V. SAI PRIYANKA, P. NEERAJA*, T. MANGILAL, M. RAVI KUMAR
}

Department of Pharmaceutics, Geethanjali College of Pharmacy, Cheeryal (V), Keesara (M), Medchal (D) - 501 301, Telangana, India. Email: neerajapodichety@gmail.com

Received: 29 August 2018, Revised and Accepted: 09 November 2018

\section{ABSTRACT}

Objective: The main objective of the present research work was to formulate and evaluate gel loaded with microspheres of apremilast to increase bioavailability and to reduce the dosing frequency and to improve patient compliance.

Methods: Gel loaded with microspheres of apremilast was prepared by solvent evaporation method by taking different ratios of polymers. Ethyl cellulose as a polymer, dichloromethane solvent is used as drug solubility, polyvinyl alcohol as a surfactant, and sodium alginate is used as gelling agent. Prepared gel loaded with microspheres was evaluated for drug interactions by Fourier transform infrared (FTIR), differential scanning calorimetry studies, and surface morphology by scanning electron microscopy (SEM), to select effective one among all formulations. The prepared formulations (F1-F6) were evaluated for pre-formulation studies, spreadability, viscosity, pH measurement, gel strength, homogeneity, drug content, in vitro diffusion studies, drug kinetics, and finally for stability studies.

Results: Differential scanning calorimeter studies confirmed that there is no drug interaction between drug and excipients. FTIR spectroscopy studies confirmed that there is compatibility between drug and excipients. Regular and spherical shape particles with smooth surface were observed in the SEM photographs. The optimized gel loaded with microspheres of F4 formulation (drug: polymer in 1:4 ratio) is more effective compared to all formulations. The prepared gel showed acceptable physical properties such as spreadability (5.86 $\pm 0.54 \mathrm{~g} . \mathrm{cm} / \mathrm{s}$ ), viscosity (568 cps), pH (6.33 \pm 0.55 ), gel strength (38 s) and drug content $(90.00 \pm 0.71 \%)$. In vitro diffusion studies have shown $80.1 \pm 1.92 \%$ drug release in $10 \mathrm{~h}$. Drug kinetics follows zero order kinetics and $\mathrm{n}$ value was found to be 0.721 . Stability studies were done for 3 months.

Conclusion: All the results show that the gel loaded with microspheres of apremilast can be effectively used for the treatment of psoriasis and psoriatic arthritis.

Keywords: Apremilast, Dichloromethane, Ethylcellulose, Gel loaded with microspheres, Polyvinyl alcohol, Sodium alginate.

(C) 2019 The Authors. Published by Innovare Academic Sciences Pvt Ltd. This is an open access article under the CC BY license (http://creativecommons. org/licenses/by/4. 0/) DOI: http://dx.doi.org/10.22159/ajpcr.2019.v12i2.29374

\section{INTRODUCTION}

Psoriasis and psoriatic arthritis are a chronic skin disease of autoimmune system that is identified as patches of abnormal skin [1]. Apremilast inhibits the enzyme phosphodiesterase 4 which leads to spontaneous inhibition of tumor necrosis factor-alpha production from human rheumatoid synovial cell [2]. In addition, the application of oral drug delivery has numerous problems such as abdominal pains, upper respiratory, nasopharyngitis, and depression that often ends in lack of patient compliance [3]. Drugs that are not soluble in water can be entrapped in microsponge pores, which are extremely small, thus the drug functions as microscopic particles, producing a greater surface area and increasing the rate of solubilization [4].

Microspheres defined as solid spherical particles, approximately the size ranges from 1 to $1000 \mu \mathrm{m}$ containing dispersed drug molecules either in solution or crystalline forms [5]. They are shallow spherical, free-flowing powders consisting of proteins polymers or synthetic polymers which are biodegradable in nature [6].

Microspheres are a polymeric matrix system which contains the drug in a state of uniform distribution throughout the matrix. Polymers such as ethyl cellulose are used for the preparation of matrix-type microspheres of water-soluble drugs to control the dissolution rate of drugs from the dosage forms [7]. Transdermal gels are a semisolid system, they prepared from a liquid which is thickened with other ingredients. The drug release through skin membrane and preparation of gelling agent sodium alginate is used [8]. The present work is to increase bioavailability and reduce the dosing frequency and improve patient compliance by designing formulation and evaluation of gel loaded with microspheres of apremilast for treating psoriasis and psoriatic arthritis.

\section{MATERIALS AND METHODS}

\section{Materials}

Apremilast (Gift sample by Alembic Pharmaceuticals Limited, Vadodara, India), It is a water-insoluble drug, so it is chosen as a main drug. Ethyl cellulose was used as a polymer (Qualikems Fine Chem Pvt., Ltd.). Polyvinyl alcohol is used as a surfactant (Qualikems Fine Chem Pvt., Ltd., Vadodara, India). Sodium alginate is used as a gelling agent (NR Chem, Mumbai). Dichloromethane is used as drug solubility (Qualikems Fine Chem Pvt., Ltd.).

\section{Methods}

Formulation of gel loaded with microsphere

Preparation of apremilast microspheres

Using solvent evaporation method, apremilast microspheres were prepared. By taking ethyl cellulose as a polymer and solution of dichloromethane solvent were used with combination to get perfect dissolution of drug in it. Initially, formulation was developed to select a best-suited solvent system for selected solvent evaporation method. The drug and polymer ratio concentration was remained constant for the formulation F1-F6. Desired quantity of ethyl cellulose polymer was dissolved in $10 \mathrm{ml}$ dichloromethane solvent. Calculated drug was added 
to this polymer solution and mixed uniformly using ultrasonication water bath for $5 \mathrm{~min}$. Take $0.5 \% \mathrm{w} / \mathrm{v}$ polyvinyl alcohol in another beaker heat it for $60^{\circ} \mathrm{C}$ for $10-15 \mathrm{~min}$. The resultant mixture was mixed thoroughly. In this, polyvinyl alcohol solution add dropwise of drug + polymer + dichloromethane solvent by continuous stirring at 300-1000 rpm for $3 \mathrm{~h}$ to produce microspheres. Formed microspheres were collected by vacuum filtration and dried at room temperature for $24 \mathrm{~h}$ to get free-flowing microspheres (Fig. 1).

Preparation of gel loaded with microspheres

Take $2 \% \mathrm{w} / \mathrm{v}$ sodium alginate and water was added by continuous stirring at 1000-1200 rpm and the resultant mixture was mixed thoroughly. In this sodium alginate gel add prepared microspheres, they should get uniformly dispersed in gel by magnetic stirring for $10 \mathrm{~min}$ to form gel loaded with microspheres (Fig. 2) [4]. The detailed composition of various formulations was prepared and mentioned in Table 1.

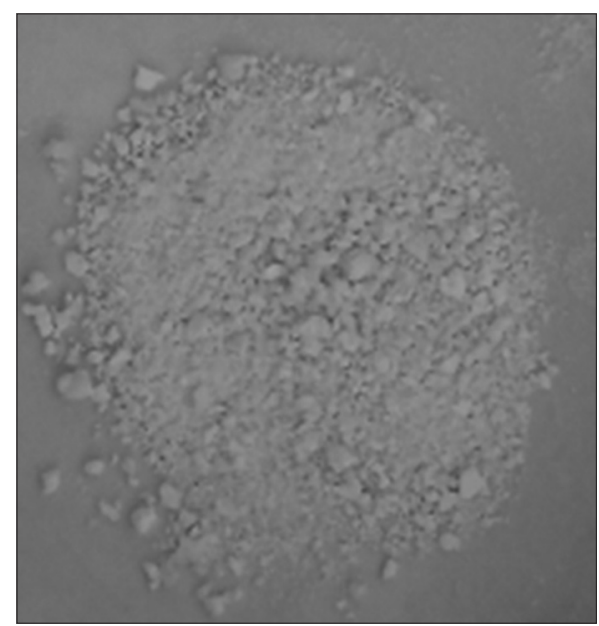

Fig 1: Apremilast microspheres

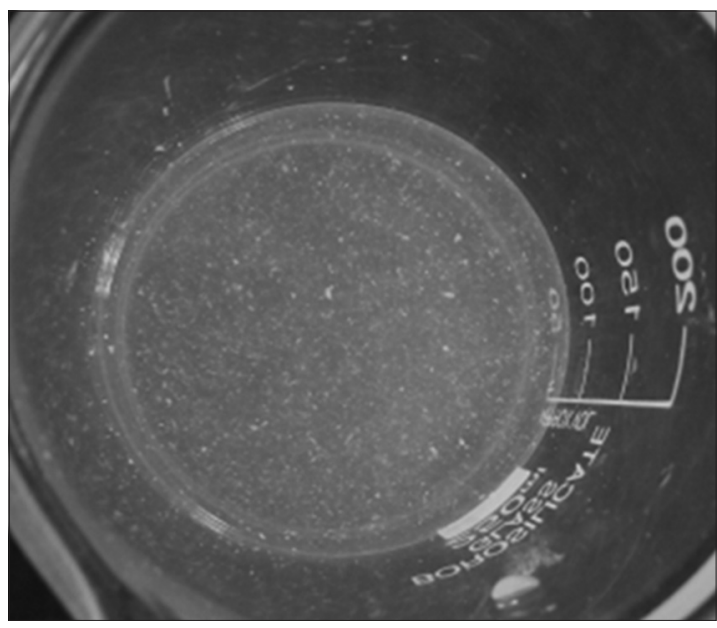

Fig 2: Gel loaded with microspheres of apremilast

\section{EVALUATION TESTS}

Evaluation of microspheres

Scanning electron microscopy (SEM)

SEM was used to determine the particle size distribution, surface topography, and texture. The microspheres were viewed at accelerated voltage of 1000 volts.

\section{Differential scanning calorimetry (DSC)}

The thermogram of pure drug, pure polymer, and drug-loaded microspheres was obtained at a scanning rate of $20^{\circ} \mathrm{C} / \mathrm{min}$ over a temperature vary of $154.1^{\circ} \mathrm{C}$

\section{Evaluation of gel loaded with microspheres}

Viscosity of the gel was determined using Brookfield viscometer evaluation of gel is determined by calculating gel strength, homogeneity, and $\mathrm{pH}[9]$.

\section{Spreadability}

About $1 \mathrm{~g}$ of gel was placed at the center of glass slide. Next, the weight of $1000 \mathrm{~g}$ was carefully applied on the upper side of the slide after $5 \mathrm{~min}$. Weight of $150 \mathrm{~g}$ is gradually added to pan to the upper slide by means of string and hook. Note the time at which the upper slide moves little over the lower slide and this was taken as a measurement of spreadability can be calculated using formula:

$S=M L / T$.

Drug and polymer interaction study Fourier transform infrared (FTIR)

FTIR spectroscopy was performed on FTIR spectrophotometer and it is used to study and find out whether there are any interactions between the drug and excipients used in the formulation.

\section{Drug content}

Weighed quantity $(10 \mathrm{mg}$ ) of developed gel loaded with microspheres was taken and dissolved in $100 \mathrm{ml}$ methanol. Then, the solution was kept in an ultrasonication water bath for 5 min to get a uniform mixture. Later, absorbance of prepared solution was measured using ultravioletvisible (UV) spectrophotometer at $263 \mathrm{~nm}$ [10].

\section{In vitro diffusion study}

Using modified apparatus of cellophane membrane was used to study the in vitro release of microspheres loaded gel formulation. Before using cellophane membrane, it should be soaked in a dissolution medium and it is tied to one end of a glass cylinder (open at both the ends). The dissolution medium was filled with a phosphate buffer (pH 6.8). $10 \mathrm{mg}$ of drug-containing gel loaded with microspheres was placed into this assembly. The cylinder was connected to a stand and suspended in dissolution medium. The dissolution medium was kept at room temperature and stirred at $100 \mathrm{rpm}$ using Teflon-coated magnetic bead. The test was taken place for about $10 \mathrm{~h}$. For every hour, $5 \mathrm{ml}$ was withdrawn with aliquots, and it is going to be filled with equal volume of receptor medium. The sample was diluted and measured using UV spectrophotometer at $263 \mathrm{~nm}$.

\section{In vitro drug kinetic studies}

To analyze the mechanism of drug release kinetics was obtained by zero order, first order, Higuchi's, and Korsmeyer-Peppas model. If

Table 1: Composition of formulations from F1 to F6

\begin{tabular}{|c|c|c|c|c|c|}
\hline Formulations code & Drug (Apremilast) (mg) & Polymer (ethyl cellulose) (mg) & DCM solvent & Polyvinyl alcohol (\%) & Sodium alginate (\%) \\
\hline F1 & 100 & 100 & 10 & 0.5 & 2 \\
\hline $\mathrm{F} 2$ & & 200 & & & \\
\hline F3 & & 300 & & & \\
\hline $\mathrm{F} 4$ & & 400 & & & \\
\hline F5 & & 500 & & & \\
\hline F6 & & 600 & & & \\
\hline
\end{tabular}




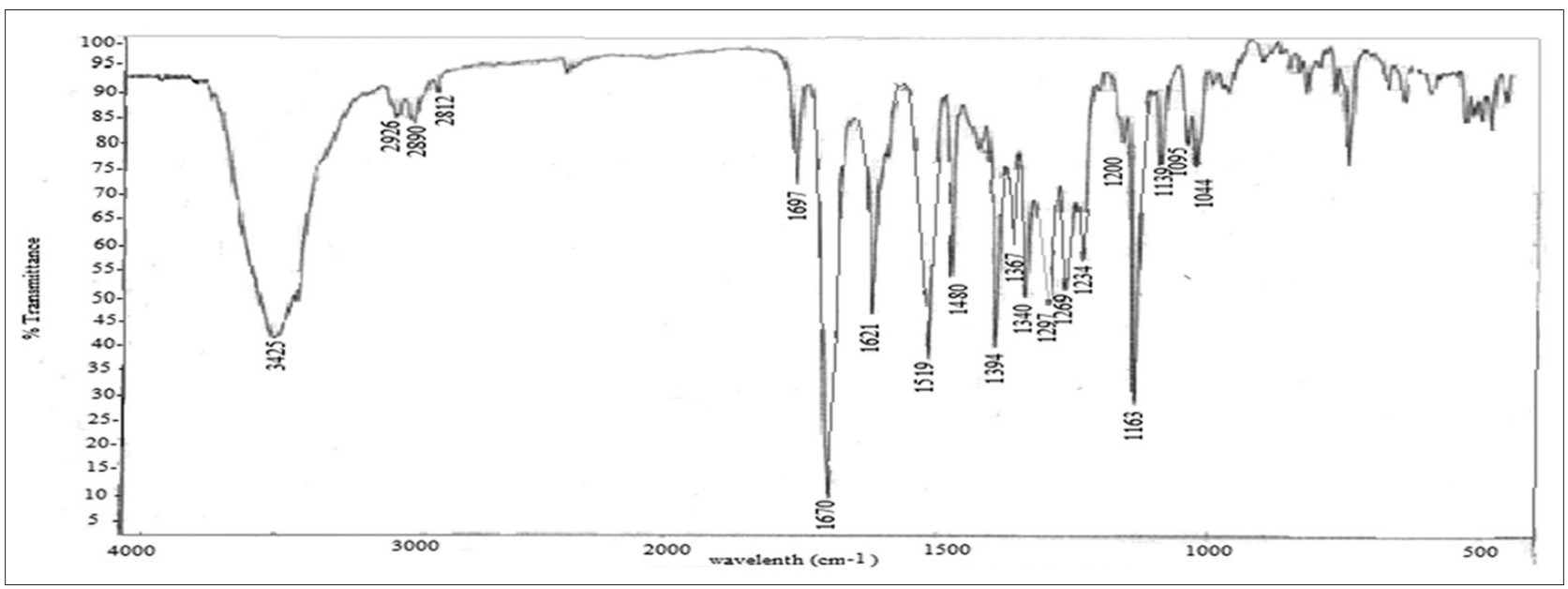

Fig. 3: Fourier transform infrared spectra of apremilast

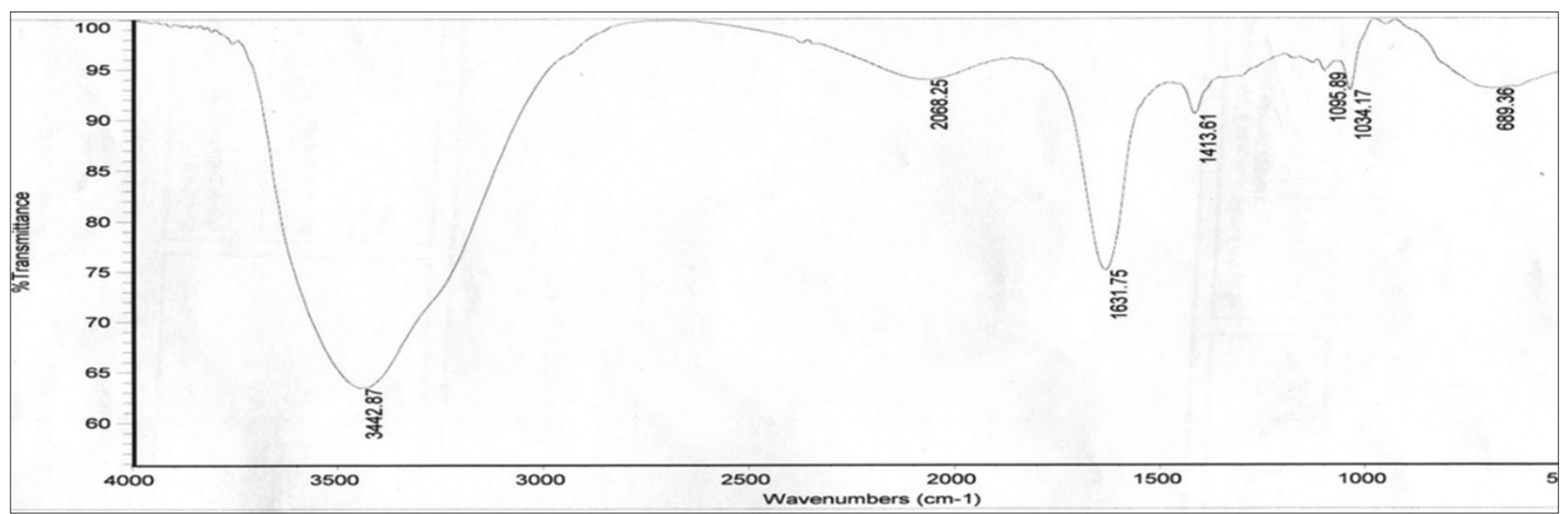

Fig. 4: Fourier transform infrared spectra of optimized formulation

$n=0.45$, the release is by Fickian diffusion, and if $n=0.89$, the release is zero order, and if $0.45<\mathrm{n}<0.89$, then the release is through non-Fickian diffusion or anomalous diffusion.

\section{Stability studies}

Selected drug loading formulations were subjected to stability study. Formulations were stored at glass container for 3 months at $30^{\circ} \mathrm{C}$ and at $75 \%$ relative humidity (RH). The F 4 formulation was evaluated for 3 months and sample stability was carried out for visual inspection, stability was evaluated by the measurement of $\mathrm{pH}$, spreadability, and drug content [11].

\section{RESULTS AND DISCUSSION}

FTIR spectrum of pure apremilast and with excipient

FTIR spectra for the formulation and pure drug are shown in Fig. 3 and 4. The spectrum of pure drug and formulation F4 presented characteristic peaks at $3425 \mathrm{~cm}^{-1}$ and $3442.87 \mathrm{~cm}^{-1}$ (amine or amide $\mathrm{N}-\mathrm{H}$ ), $1621 \mathrm{~cm}^{-1}$ and $1631.75 \mathrm{~cm}^{-1}$ (alkene $\mathrm{C}=\mathrm{C}$ ), $1340 \mathrm{~cm}^{-1}$ and $1413.61 \mathrm{~cm}^{-1}$ (alkane $-\mathrm{C}-\mathrm{H}$ ), $1095 \mathrm{~cm}^{-1}$ and $1095.89 \mathrm{~cm}^{-1}$ (C-OH), and $1044 \mathrm{~cm}^{-1}$ and $1034.17 \mathrm{~cm}^{-1}$ (ester C-0). This indicates that the drug was compatible with excipients.

\section{Evaluation of microspheres}

\section{SEM}

SEM photograph of F4 formulation of 1:4 ratio is shown in Fig. 6. Surface smoothness of apremilast microspheres was discrete, large size and showed less aggregation with spherical and uniform free flowing which was confirmed by SEM. At lower concentration, F2 formulation of (1:2 ratio) surface was rough (Fig. 5) [12].
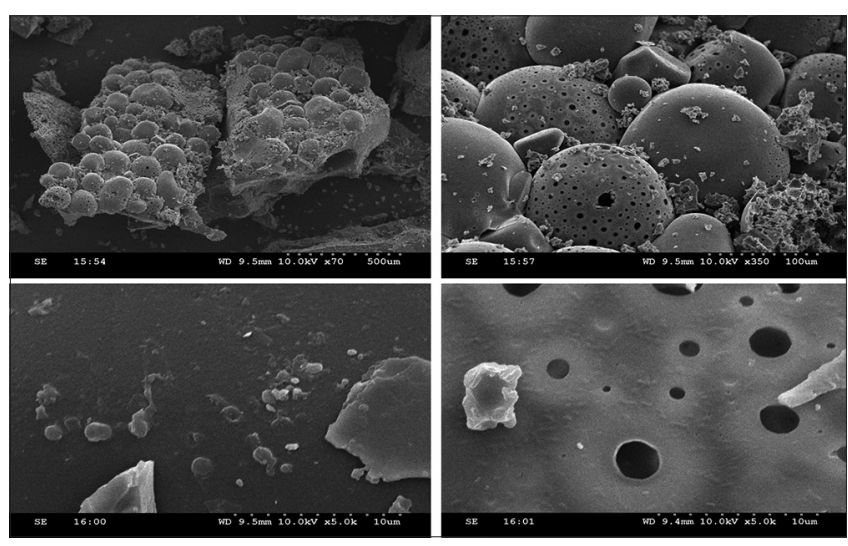

Fig5: Scanning electron microscopy photographs of F4 formulation

DSC

The pure apremilast showed a sharp endothermic peak at $156.1^{\circ} \mathrm{C}$ and some similar changes occur in endothermic peak were observed at similar temperature in prepared formulation at $154.2^{\circ} \mathrm{C}$. Thus, it is concluded that there is no drug excipients interaction (Fig. 7).

\section{Evaluation of gel-loaded microspheres \\ Viscosity studies}

The viscosity of F1, F2, F3, F4, F5, and F6 formulations shows that the concentration of polymer increases, viscosity of gel formulation also 
increases. However, at the higher concentration of polymer may affect the spreadability of gel formulation. From the results, it was concluded that the formulation F4 showed maximum viscosity, that is, $568 \mathrm{cps}$ and

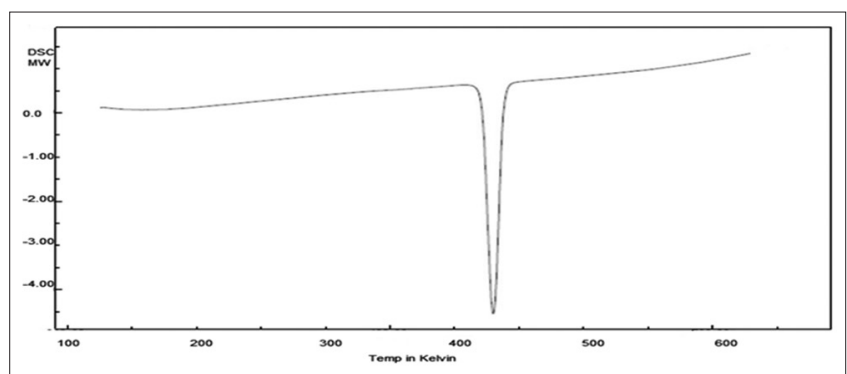

Fig. 6: Differential scanning calorimetry of apremilast

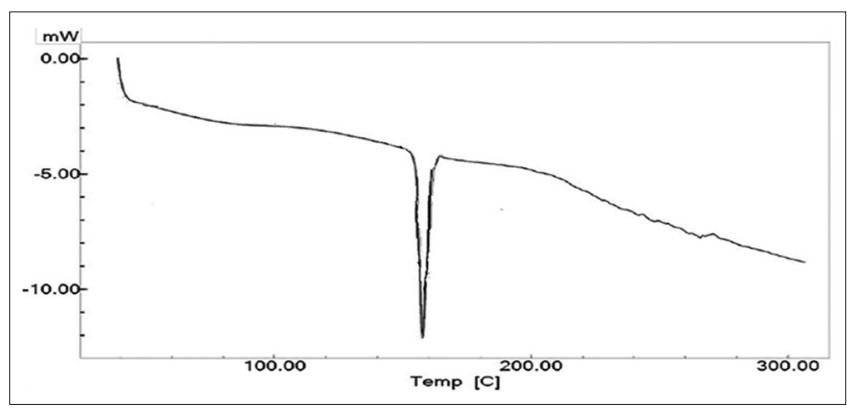

Fig 7: Differential scanning calorimetry of gel loaded with microspheres of apremilast

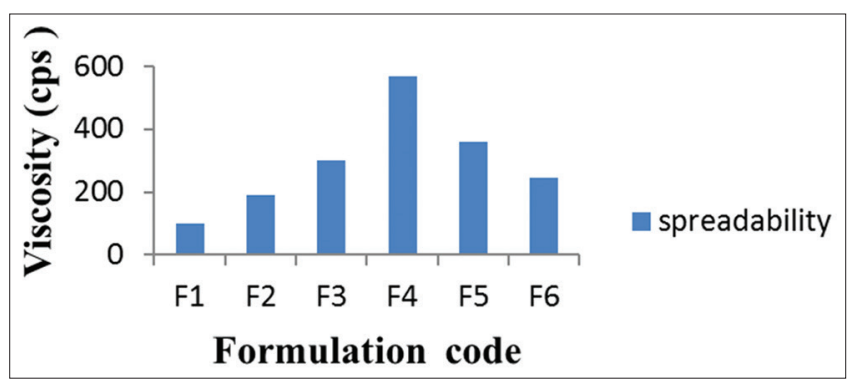

Fig 8: Viscosity of gel loaded with microspheres of apremilast

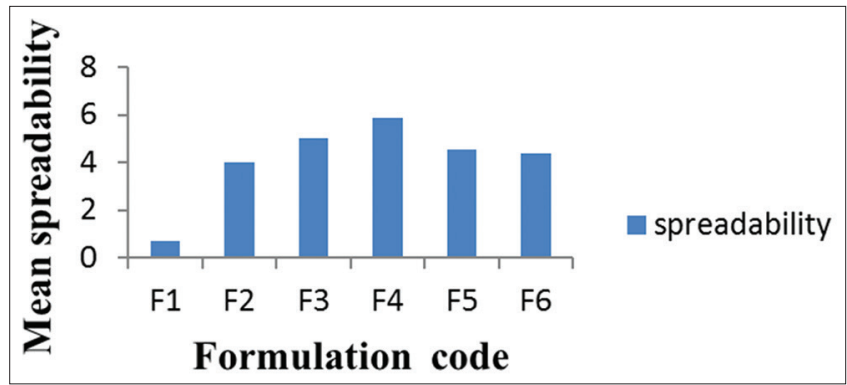

Fig. 9: Spreadability of gel loaded with microsphere of apremilast formulation F1 showed minimum viscosity, that is, $100 \mathrm{cps}$ (Fig. 8). The value of viscosity is shown in Table 2 .

\section{Gel strength}

Gel strength is important because strong gels will support a much higher pressure than weak gels before they are washed out of the targeted site. It is calculated in time (s) and found within the range of 15-38 s. The values of gel strength are shown in Table 2.

\section{Homogeneity}

All developed gels showed good homogeneity with the absence of lumps. The developed preparations were much clear and transparent [13]. The results are shown in Table 2 .

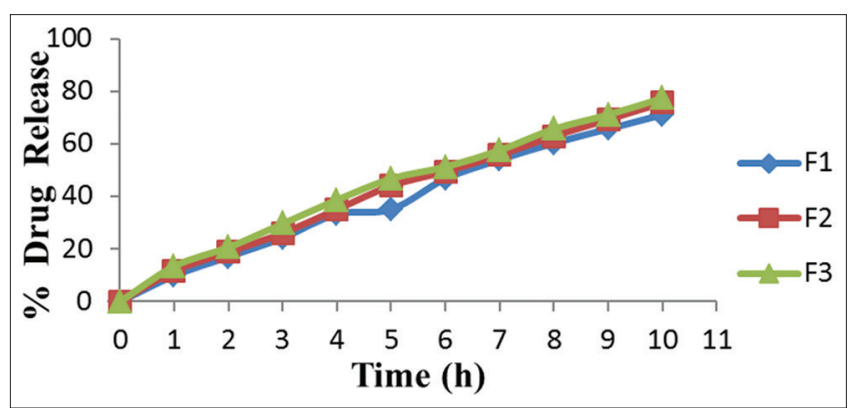

Fig. 10: In vitro percentage drug release of formulation code of F1-F3

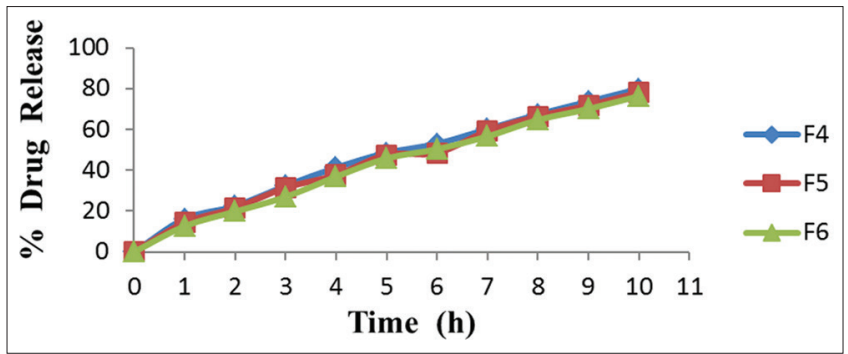

Fig. 11: In vitro percentage drug release of formulation code of F4-F6

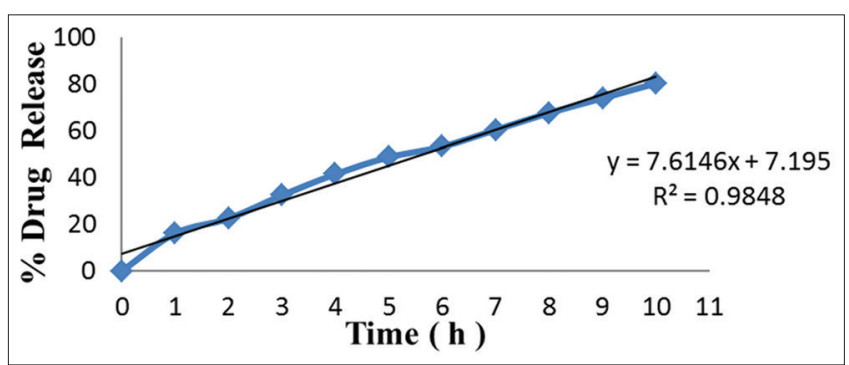

Fig. 12: Graphical presentation of zero-order release kinetics

Table 2: Viscosity, gel strength, homogeneity, and pH of formulation code of F1-F6

\begin{tabular}{lllll}
\hline Formulation code & Viscosity (cps) & Gel strength (s) & Homogeneity & pH \\
\hline F1 & 100 & 15 & Satisfactory & $5.53 \pm 0.41$ \\
F2 & 190 & 22 & Good & $6.23 \pm 0.73$ \\
F3 & 300 & 35 & Good & $6.16 \pm 0.87$ \\
F4 & 568 & 38 & Excellent & $6.33 \pm 0.55$ \\
F5 & 360 & 26 & Satisfactory & $7.00 \pm 0.2$ \\
F6 & 240 & 32 & Good & $7.20 \pm 0.3$ \\
\hline
\end{tabular}




\section{Measurement of $\mathrm{pH}$}

The $\mathrm{pH}$ values of all formulations of gel were in a range of $5.53 \pm 0.41$ to $7.20 \pm 0.3$ which is well within the limits of skin $\mathrm{pH}$, that is, 5.6-7.5. Hence, it was concluded that all formulations could not produce any local irritation to the skin [14]. The results are shown in Table 2.

\section{Spreadability}

The spreadability of gel loaded with microspheres was found to be $0.7 \pm 0.47 \mathrm{~g} \mathrm{~cm} / \mathrm{s}-5.86 \pm 0.54 \mathrm{~g} . \mathrm{cm} / \mathrm{s}$. The result is shown in Table 3 compared to all formulations F4 formulation indicated a good spreadability (Fig. 9).

\section{Drug content}

The percentage drug content of all prepared gel loaded with microspheres formulations is in the range of 77.02 $\pm 0.19-90.00 \pm 0.71$. The result is shown in Table 3 compared to all formulations F4 formulation indicated a good drug content.

\section{In vitro diffusion studies}

The diffusion studies were carried out using cellophane membrane using phosphate buffer ( $\mathrm{pH} \mathrm{6.8)}$ as a dissolution medium for $10 \mathrm{~h}$. The drug release was increased with decreased due to increase in polymer concentration (Table 4) [15]. Compared all formulations F4 formulation shows best drug release at $10 \mathrm{~h}$ (Figs 10 and 11).

\section{Drug release kinetics of in vitro studies}

In vitro drug release kinetics data of $\mathrm{F} 4$ formulation were subjected to release kinetic study according to zero order, first order, Higuchi model, and Korsmeyer-Peppas equation to find out the mechanism of drug release [16].

It was found that the $\mathrm{F} 4$ formulation follows the zero-order kinetics and it shows the best correlation by the Higuchi model proving that the release is by diffusion mechanism. Moreover, Korsmeyer-Peppas model showed anomalous mode of drug release (Tables 5 and 6). $n$ value of Korsmeyer-Peppas model for gel loaded with microspheres of apremilast formulation is 0.721 (Figs. 12-15).

Table 3: Spreadability and drug content of formulation code of F1-F6

\begin{tabular}{lll}
\hline $\begin{array}{l}\text { Formulation } \\
\text { code }\end{array}$ & $\begin{array}{l}\text { Spreadability* } \\
\text { (g.cm/s) }\end{array}$ & Drug content (\%)* \\
\hline F1 & $0.7 \pm 0.47$ & $77.02 \pm 0.19$ \\
F2 & $4.03 \pm 0.16$ & $80.57 \pm 0.35$ \\
F3 & $5.01 \pm 0.24$ & $85.00 \pm 0.21$ \\
F4 & $5.86 \pm 0.54$ & $90.00 \pm 0.71$ \\
F5 & $4.57 \pm 0.65$ & $87.81 \pm 0.53$ \\
F6 & $4.37 \pm 0.20$ & $84.83 \pm 0.42$ \\
\hline
\end{tabular}

*Mean \pm SD, n=3. SD: Standard deviation
Stability studies

The stability studies were carried out for 3 months at $30^{\circ} \mathrm{C}$ and at $75 \%$ RH. No major changes occur in following parameters such as measurement of $\mathrm{pH}$, spreadability, and drug content. Thus, it can be concluded that the $\mathrm{F} 4$ formulation is in stable condition (Table 7).

The application of the oral drug delivery of apremilast has numerous problems such as lesser bioavailability, diarrhea, vomiting, loss of appetite, and headache [2]. To overcome these problems, it is attempted to formulate gel loaded with microspheres of apremilast using solvent evaporation method. F1-F6 formulation was prepared using different concentration of polymer ratio. Apremilast in 1:4 (F4) ratio produces better spreadability, viscosity, and gel strength

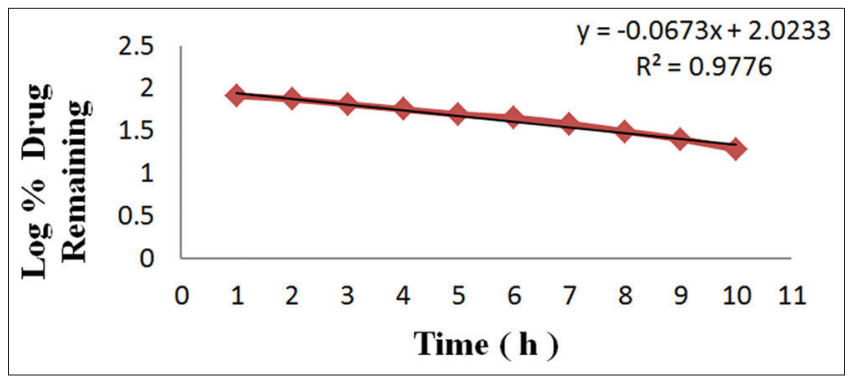

Fig. 13: Graphical presentation of first-order kinetics

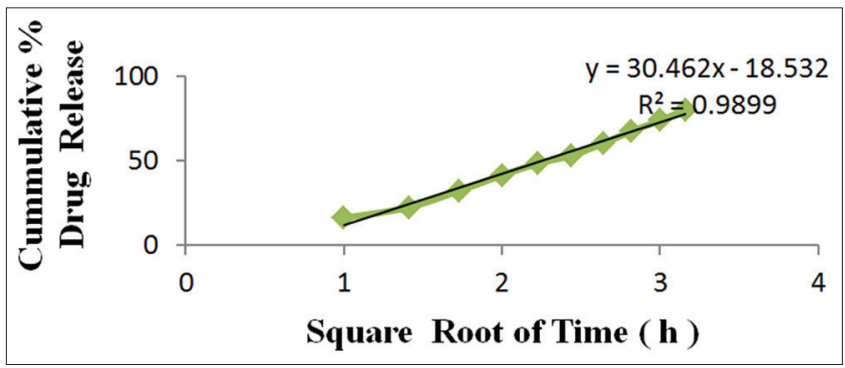

Fig. 14: Graphical presentation of Higuchi model

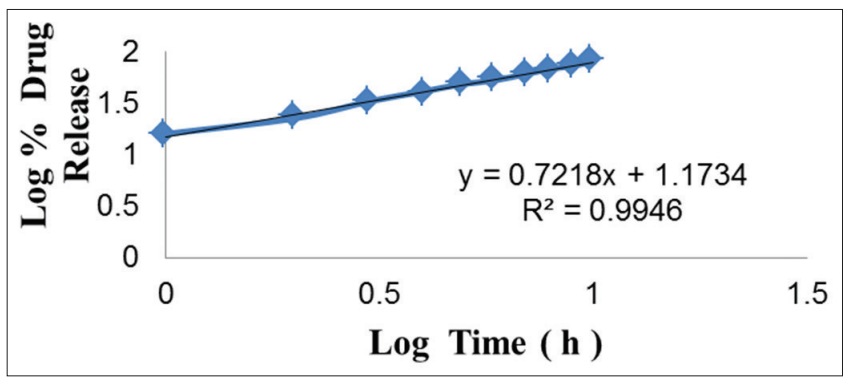

Fig. 15: Graphical presentation of Korsmeyer-Peppas model

Table 4: Percent drug release of all formulation codes of F1-F6

\begin{tabular}{|c|c|c|c|c|c|c|}
\hline Time (h) & F1 & F2 & F3 & F4 & F5 & F6 \\
\hline 0 & 0 & 0 & 0 & 0 & 0 & 0 \\
\hline 1 & $9.9 \pm 0.19$ & $11.7 \pm 0.21$ & $13.5 \pm 0.34$ & $16.2 \pm 0.55$ & $14.4 \pm 0.25$ & $12.6 \pm 0.20$ \\
\hline 2 & $17.1 \pm 0.23$ & $18.9 \pm 0.28$ & $20.7 \pm 0.39$ & $22.5 \pm 0.72$ & $21.6 \pm 0.33$ & $19.8 \pm 0.26$ \\
\hline 3 & $24.3 \pm 0.28$ & $26.1 \pm 0.32$ & $29.7 \pm 0.48$ & $32.4 \pm 0.89$ & $31.5 \pm 0.42$ & $27.0 \pm 0.31$ \\
\hline 4 & $33.3 \pm 0.32$ & $35.1 \pm 0.39$ & $38.7 \pm 0.53$ & $41.4 \pm 0.96$ & $37.8 \pm 0.48$ & $36.9 \pm 0.35$ \\
\hline 5 & $35.1 \pm 0.36$ & $44.1 \pm 0.45$ & $46.8 \pm 1.02$ & $48.6 \pm 1.25$ & $47.7 \pm 0.66$ & $45.9 \pm 0.40$ \\
\hline 6 & $46.8 \pm 0.45$ & $49.5 \pm 0.50$ & $51.3 \pm 1.24$ & $53.1 \pm 1.38$ & $48.6 \pm 0.78$ & $50.4 \pm 0.49$ \\
\hline 8 & $61.2 \pm 0.56$ & $63.0 \pm 0.64$ & $65.7 \pm 1.44$ & $67.5 \pm 1.52$ & $66.6 \pm 0.98$ & $64.8 \pm 0.61$ \\
\hline 9 & $65.7 \pm 0.70$ & $69.3 \pm 0.72$ & $71.1 \pm 1.56$ & $73.8 \pm 1.68$ & $72.0 \pm 1.21$ & $70.2 \pm 0.68$ \\
\hline 10 & $71.1 \pm 0.79$ & $75.6 \pm 0.85$ & $77.4 \pm 1.69$ & $80.1 \pm 1.92$ & $78.3 \pm 1.30$ & $76.5 \pm 0.83$ \\
\hline
\end{tabular}


Table 5: Drug release kinetics of gel loaded with microspheres

\begin{tabular}{|c|c|c|c|c|c|c|c|}
\hline \multicolumn{2}{|c|}{ Zero order } & \multicolumn{2}{|c|}{ First order } & \multicolumn{2}{|l|}{ Higuchi's model } & \multicolumn{2}{|c|}{ Korsmeyer-Peppas } \\
\hline Time (h) & $\begin{array}{l}\text { Cumulative \% drug } \\
\text { release }\end{array}$ & Time (h) & $\begin{array}{l}\text { Log } \% \text { of drug } \\
\text { remaining }\end{array}$ & $\begin{array}{l}\text { Square root of } \\
\text { time (h) }\end{array}$ & $\begin{array}{l}\text { Cumulative \% drug } \\
\text { release }\end{array}$ & $\begin{array}{l}\text { Log } \\
\text { time (h) }\end{array}$ & $\begin{array}{l}\text { Log \% drug } \\
\text { release }\end{array}$ \\
\hline 2 & 22.58 & 2 & 1.88 & 1.41 & 22.58 & 0.30 & 1.35 \\
\hline 3 & 32.51 & 3 & 1.82 & 1.73 & 32.51 & 0.47 & 1.51 \\
\hline 4 & 41.56 & 4 & 1.76 & 2 & 41.56 & 0.60 & 1.61 \\
\hline 5 & 48.80 & 5 & 1.70 & 2.23 & 48.80 & 0.69 & 1.68 \\
\hline 6 & 53.34 & 6 & 1.66 & 2.44 & 53.34 & 0.77 & 1.72 \\
\hline 7 & 60.56 & 7 & 1.59 & 2.64 & 60.56 & 0.84 & 1.78 \\
\hline 8 & 67.80 & 8 & 1.50 & 2.80 & 67.80 & 0.90 & 1.83 \\
\hline 9 & 74.13 & 9 & 1.41 & 3 & 74.13 & 0.95 & 1.86 \\
\hline 10 & 80.47 & 10 & 1.29 & 3.16 & 80.47 & 1 & 1.90 \\
\hline
\end{tabular}

Table 6: Regression coefficient $\left(\mathrm{R}^{2}\right)$ of different drug kinetic model and diffusion exponent (N) of Korsmeyer-Peppas model

\begin{tabular}{|c|c|c|c|c|}
\hline \multicolumn{2}{|c|}{ Formulation } & \multicolumn{2}{|c|}{ Regression coefficient } & \multirow{2}{*}{$\frac{\text { Slope (n) value }}{\text { Korsmeyer-Peppas }}$} \\
\hline Code & Zero order & First order & Higuchi & \\
\hline F4 & 0.984 & 0.977 & 0.989 & 0.721 \\
\hline
\end{tabular}

Table 7: Stability studies of optimized formulation (F4)

\begin{tabular}{|c|c|c|c|c|}
\hline Formulation code & Time (months) & pH * & Spreadability* (g. cm/s) & Drug content* $(\%)$ \\
\hline \multirow[t]{4}{*}{ F4 } & 0 & $6.33 \pm 0.55$ & $5.86 \pm 0.54$ & $90.00 \pm 0.71$ \\
\hline & $1^{\text {st }}$ & $6.30 \pm 0.42$ & $5.66 \pm 0.32$ & $89.63 \pm 0.63$ \\
\hline & $2^{\text {nd }}$ & $6.12 \pm 0.12$ & $4.98 \pm 0.12$ & $88.54 \pm 0.32$ \\
\hline & $3^{\text {rd }}$ & $6.05 \pm 0.43$ & $4.72 \pm 0.63$ & $88.22 \pm 0.10$ \\
\hline
\end{tabular}

${ }^{*}$ Mean \pm SD. SD: Standard deviation

when compared to other formulations. SEM studies of prepared microspheres were within the range of $1-1000 \mu \mathrm{m}$. There is no drug excipients interaction in FTIR and DSC. The formulation of F4 showed good consistency and homogeneity, the $\mathrm{pH}$ is within the limit of skin so no skin irritation. The percent drug content was found to be $90.00 \pm 0.71 \%$. The in vitro percentage drug release was found to be $80.1 \pm 1.92 \%$ in $10 \mathrm{~h}$ and drug kinetics follows zero-order kinetics, and moreover, Korsmeyer-Peppas model showed anomalous mode of drug release, in F4 formulation. Stability studies were conducted for a period of 3 months.

\section{CONCLUSION}

Gel loaded with microspheres of apremilast was prepared with aim to deliver the drug which passes through transdermal route as it provides quick onset of action when compared to oral route. This gel loaded with microspheres of apremilast was successfully prepared using solvent evaporation method by taking different concentration of polymer ratio.

\section{ACKNOWLEDGMENT}

We are very grateful to Geethanjali College of Pharmacy, Cheeryal, Hyderabad, for providing the essential facilities to execute this work.

\section{CONFLICTS OF INTEREST}

The authors declare that this paper content has no conflicts of interest.

\section{AUTHORS' CONTRIBUTIONS}

The work was carried out in collaboration between all the authors. Authors NVS and PN carried out the formulation and evaluation activities and drafted the manuscript. Authors TM and MRK managed the analysis of the study and literature searches. The article was read and approved by all the authors.

\section{REFERENCES}

1. Tang M, Hu P, Huang S, Zheng Q, Yu H, He Y, et al. Development of an extended-release formulation for apremilast and a level A in vitroin vivo correlation study in beagle dogs. Chem Pharm Bull (Tokyo) 2016;64:1607-15.

2. Vangipuram R, Alikhan A. Apremilast for the management of moderate to severe plaque psoriasis. Expert Rev Clin Pharmacol 2017;10:349-60.

3. Ighani A, Georgakopoulos JR, Zhou LL, Walsh S, Shear N, Yeung $\mathrm{J}$, et al. Efficacy and safety of apremilast monotherapy for moderate to severe psoriasis: Retrospective study. J Cutan Med Surg 2018;22:290-6.

4. Kumar JR, Muralidharan S, Parasuraman S. In vitro and in vivo evaluation of microspheres loaded topical gel delivery system of ketoconazole in male rats against Candida glabrata. J Pharm Sci Res 2014;6:376-81.

5. Kadam NR, Suvarna V. Microspheres: A brief review. Asian J Biomed Pharm Sci 2015;5:13-9.

6. Jamini M, Rawat S. A review on microsphere. Res J Pharm Boil Chem Sci 2013;4:1223-3.

7. Preeti A, Sarlesh R, Ashish P, Shrivas NT, Singh SB, Singh RB. Microspheres a magical novel drug delivery system: A review. World J Pharm Pharm Sci 2012;1:439-55.

8. Darshan K, Rajinder S. A novel approach: Transdermal gel. Int J Pharm Res Rev 2015;4:41-50.

9. Basha NB, Prakasam K, Divakar G. Formulation and evaluation of gel containing fluconazole antifungal agent. Int J Drug Dev Res 2011;3:109-28.

10. Banasmita K, Kritika S, Bhupen K. Formulation and evaluation of metronidazole microspheres-loaded bioadhesive vaginal gel. Asian J Pharm Clin Res 2017;10:418-24.

11. Prasanth VV, Chakraborty A, Mathew ST, Rinku M, Kamalakkannan V. Formulation and evaluation of salbutamol sulphate microspheres by solvent evaporation method. J Appl Pharm Sci 2011;1:133-7.

12. Asif HM, Kumar AR, Rao RT, Anjum M. Preparation and evaluation of ethyl cellulose microspheres prepared by solvent evaporation technique. Int J Pharm Pharm Sci 2014;6:264-6.

13. Baviska DT, Biranwar YA, Bare KR, Parik VB, Sapate MK, Jain DK. In vitro and in vivo evaluation of diclofenac sodium gel prepared with 
cellulose ether and carbopol 934P. Trop J Pharm Res 2013;12:489-94.

14. Sanju N, Kamal S, Sharma B. Formulation, evaluation and optimization of transdermal gel of ketorolac tromethamine using face centered central composite design. Int J Pharm Pharm Sci 2014;6:133-9.

15. Hiren P, Panchal MS, Suresh S, Vadalia KR. Formulation and evaluation of transdermal gel of sildenafil citrate. Int J pharm Res Allied Sci 2012;1:103-8

16. Satyabrata B, Kumar KP, Sudhakar M, kumar AD. Formulation and evaluation of diclofenac transdermal gel. J Adv Pharm Edu Res $2013 ; 3: 248-59$ 